\title{
Comparison Between Cemented and Uncemented Hemiarthroplasty in Patients With Femoral Neck Fractures: A Systematic Review and Meta- analysis
}

Xiu Mei Tang

Sichuan University West China Hospital

Duan Wang

Sichuan University West China Hospital

Ying Liu

Sichuan University West China Hospital

Jia Li Chen

Sichuan University West China Hospital

Pei Fang Li

Sichuan University West China Hospital

Zong Ke Zhou

Sichuan University West China Hospital

Ning Ning ( $\nabla$ ningning6405@163.com)

West China School of Nursing /West China Hospital, Orthopedics Department, Sichuan University, Chengdu, 610041, P.R. China.

Research article

Keywords: Hemiarthroplasty, Cemented, Uncemented, Outcomes, Femoral Neck Fractures, Complications

Posted Date: September 8th, 2020

DOI: https://doi.org/10.21203/rs.3.rs-61772/v1

License: (9) (7) This work is licensed under a Creative Commons Attribution 4.0 International License. Read Full License 


\section{Abstract}

\section{Background}

We performed an updated systematic review and meta-analysis to compare the outcomes of CHA and UCHA in patients with FNFs.

\section{Methods}

We searched 6 English databases (Cochrane Library, ScienceDirect, PubMed, Embase, Medline, and Web of Science) and 4 Chinese databases (CNKI, VIP, Wang Fang, and Sino Med) in July 2020. The quality of each study was assessed according to the Cochrane handbook of systematic reviews. Data were pooled as risk ratios (RRs) and weighted mean differences (WMDs) with $95 \%$ confidence intervals ( $95 \%$ Cls). We used the random-effects model despite the heterogeneity among the studies. Data regarding baseline characteristics, hip function, complications both prosthetic-related and common, and operative outcomes are reported.

\section{Results}

A total of 24 RCTs based on 22 trials involving 3119 patients (CHA, 1575; UCHA, 1544) were included. Patients in CHA group show better hip function with HHS within 6 weeks (WMD =9.097, 95\% Cl, 3.034-15.161; $\mathrm{P}<0.003), 3$ months (WMD=3.347, 95\% Cl, 1.478-5.216; $\mathrm{P}<0.001), 12$ months $(\mathrm{WMD}=2.183,95 \% \mathrm{Cl}$, 0.161-4.205; $\mathrm{P}=0.034)$. The pooled results show that $\mathrm{CHA}$ had lower rates of refracture $(\mathrm{RR}=0.227,95 \% \mathrm{Cl}, 0.135-0.381 ; \mathrm{P}<0.0001)$, subsidence or loosening $(\mathrm{RR}=0.295,95 \% \mathrm{Cl}, 0.112,0.778 ; \mathrm{P}<0.014)$ and revision $(\mathrm{RR}=0.468,95 \% \mathrm{Cl}, 0.279-0.786 ; \mathrm{P}=0.004)$. Furthermore, $\mathrm{CHA}$ group tend to have lower pain $(\mathrm{VAS}$ score) $(\mathrm{WMD}=-0.568,95 \% \mathrm{Cl},-0.897$ to $-0.239 ; \mathrm{P}=0.001)$, lower rate of pressure injury(RR=0.432, $95 \% \mathrm{Cl}, 0.221-0.846 ; \mathrm{P}=0.014)$ and mortality at 1 year after surgery $(R R=0.852,95 \% \mathrm{Cl}, 0.727-0.998 ; \mathrm{P}=0.047)$. UCHA showed a shorter operative duration( $\mathrm{WMD}=8.739,95 \% \mathrm{Cl}, 6.354-11.124 ; \mathrm{P}<0.0001)$.

\section{Conclusions}

This meta-analysis demonstrates that CHA has better hip function, lower rates of refracture, subsidence or loosening, revision, pressure ulcer, pain and oneyear mortality than UCHA, while UCHA has shorter operative duration.

\section{Background}

Femoral neck fractures (FNFs) are associated with high rates of mortality and functional loss among older adults. The incidence of FNF is estimated to increase to between 7 million and 21 million per year by 2050[1]. Data from Europe have revealed that cases of FNF could surge from 615000 in 2010 to 815000 in 2025 (32\%), among which the 30-day and 1-year mortality rates are more than $10 \%$ and $30 \%$, respectively[2,3]

Hemiarthroplasty (HA) is recommended for aged FNF patients to regain acceptable functional recovery and pain relief. HA as a treatment for FNF is associated with fewer prosthesis-related complications than total hip arthroplasty and has better outcomes than internal fixation[4]. There are two different types of HA: cemented hemiarthroplasty ( $\mathrm{CHA}$ ) and uncemented hemiarthroplasty (UCHA). Polymethylmethacrylate bone cement is inserted as a bone implant in $\mathrm{CHA}$, while in UCHA, the prosthesis, such as a Thompson prosthesis or modern hydroxyapatite-coated implant, is press-fit in the femur without cement.

Although 8 meta-analyses have been published[5-13], the results of modern implants had not been fully considered and previous results were inconsistent, indicating a need for more robust evidence. The most recent study carried a substantial risk of bias in its methodology due to the lack of publication bias plots and sensitivity analysis for high heterogeneity outcomes and it is not known how or to what extent these risks of bias influence the findings[14]. Ahn[13] identified 11 studies, including both prospective and retrospective studies, and concluded that CHA had a lower revision rate, and UCHA had less blood loss and a shorter operative duration[13]. This review was limited by predictable bias from quasi-RCTs or non-RCTs and showed considerable heterogeneity in most results. In the first meta-analysis composed only of RCTs, Li examined 7 RCTs and found that CHA could achieve better hip function with less pain and fewer implant-related complications in elderly patients with FNF[12]. However, they still had difficulty creating funnel plots to assess the publication bias because of the limited number of trials. Ning published an updated meta-analysis including 12 studies, the results clashed with those of previous reviews and only showed that UCHA had a longer operative duration[11]. Veldman detailed postoperative complications between $\mathrm{CHA}$ and UCHA but only enrolled 5 studies[10]. Imam summarized 9 RCTs and 20 observations and found greater intraoperative blood loss and heterotopic ossification in $\mathrm{CHA}$ [9]. CHA had a higher 1-year mortality rate in several studies, but this result was revised in a later analysis[7,5]. These studies were criticized for their patients samples, inclusion criteria, poor randomization, limited reporting of outcomes, inadequate follow-up, and exclusion of modern implants. The Cochrane review concluded that patients with cemented prostheses have less pain at one year or later and had improved postoperative mobility and no differences in mortality or complications at any time point. The authors of the review acknowledged that the majority of the included studies evaluated traditional prostheses such as the cemented Thompson and uncemented Austin Moore prostheses. Thus, despite its conclusion was in favour of cementing, the review raised the need for further comparisons between cemented and more advanced uncemented implants[28].

Earlier reviews did not include a sufficient number of RCTs, which will confound the findings. Furthermore, some researchers did not apply sensitivity analysis or subgroup analysis to determine and explain heterogeneity. Some studies excluded old trials to investigate the influence of new materials but at the expense of previous data. Though these studies compared most of the variables between CHA and UCHA, we still consider that improvements are needed based on the following reasons. First, predictable bias from quasi-RCTs or non-RCTs existed in all studies. Second, complications were roughly stratified in several reviews, and no specific syndrome was analysed. Third, the purest RCT analysis only included 12 studies in 2014. Fourth, 3 of the latest RCTs, 2 of which had large samples, were published in 2020, and another was published in 2018, and these studies were not included in previous meta-analyses[15-17]. Finally, similar studies have been carried out in China but without presenting the results for worldwide discussion. The purpose of our study was to integrate the latest 
evidence and include high-quality Chinese studies enrolled both modern implants and traditional ones to provide an updated meta-analysis comparing the outcomes of $\mathrm{CHA}$ and UCHA in patients with FNF.

\section{Methods}

\section{Search strategies}

Two investigators (TXM, WD) searched 10 data bases in July 2020. The following search terms were used: "Hemiarthroplasty" "Hemiarthroplasties", "HemiArthroplasty", "Hemi Arthroplasty”, “Hemi-Arthroplasties”, "Femoral Neck Fractures”, “Femoral Neck Fracture”, "Femur Neck Fractures”, "Femur Neck Fracture"), "Thompson/Austin Moore prostheses", "cemented", "cement", "uncemented", "un-cemented", and "cementless". References cited in relevant articles were also manually searched for relevant articles. The language was restricted to English and Chinese.

\section{Eligibility and exclusion criteria}

The inclusion criteria were as follows: studies comparing the outcomes between CHA and UCHA among FNF patients; studies with full text and data available for further meta-analysis; and RCTs.

Studies were excluded if they met the following criteria: meetings, abstracts, comments, case reports, reviews, and meta-analyses; data could not be extracted or estimated.

\section{Data extraction}

Two reviewers independently extracted relevant information from each eligible study using a standard form. Any disagreement was resolved by the adjudicating senior authors.

Data for the following outcomes were extracted: hip function (Harris hip score, HHS), complications (prosthesis-related complications and general complications) and operative outcomes.

\section{Assessment of quality}

We assessed the methodological quality of the original studies using the Cochrane handbook of systematic reviews.

\section{Statistical analysis}

We analysed the data using Stata SE12.0. The risk of bias and publication bias was analysed by RevMan 5.3. The $I^{2}$ test was used to examine heterogeneity among studies. Heterogeneity was defined as absent $\left(I^{2}=0.0 \%\right.$ to $\left.25.0 \%\right)$, low $\left(I^{2}=25.1 \%\right.$ to $\left.50.0 \%\right)$, moderate $\left(I^{2}=50.1 \%\right.$ to $\left.75.0 \%\right)$ or high $\left(I^{2}=75.1 \%\right.$ to $100.0 \%)$. The random-effects model was used despite heterogeneity. Sensitivity analysis was further performed by removing each study. Subgroup analysis was performed to compare the different follow-up points. All $\mathrm{P}$ values were two-sided and considered significant if $<0.05$.

\section{Results}

\section{Identification of studies}

A total of 1145 studies were identified by the search strategies (including searching the databases, Google Scholar, and articles retrieved in the references). After automatic duplicate removal, 639 articles were saved and 24 studies were identified[17-28,16,29,15,30-38] (Fig 1. PRISMA study flow diagram).

\section{Risk of bias and publication bias}

The risk of bias is shown in Fig 2. (Fig 2. Risk of bias graph)Funnel plots were used to investigate the risk of publication bias based on the results of outcomes enrolled more than 10 studies. (Fig 3. Publication bias).

\section{Study characteristics}

We identified 24 RCTs, with 20 in English and 4 in Chinese. All selected studies were published between 1982 and 2020 . The details of enrolled studies were shown in Table 1. (Table 1. Characteristics of the included studies)And we provide the synthesized meta-analysis outcomes in Table 2.( Table 2.Outcomes of meta-analysis)

\section{Hip function}

HHS

Altogether, 21 studies provided information regarding the HHS in different stages. In our meta-analysis, CHA has higher HHS results within 6 weeks $(\mathrm{WMD}=9.097, \mathrm{P}<0.003), 3$ months ( $\mathrm{WMD}=3.347, \mathrm{P}<0.001), 12$ months (WMD=2.183, $\mathrm{P}=0.034)$ (Fig 4. Forest plot analysis of HHS).

\section{Prothesis-related complications}

Refractures 
Nine RCTs were pooled together and indicated that CHA resulted in fewer refractures than UCHA $(R R=0.227, P<0.0001)($ Fig 5. Forest plot analysis of Refracture).

Subsidence or loosening

Our study find that CHA has lower rates of subsidence or loosening compared with UCHA $(R R=0.295 ; P<0.014)$

Revision

The pooled results showed that $\mathrm{CHA}$ contributed more to reducing the reoperation rate $(\mathrm{RR}=0.468, \mathrm{P}=0.004)$

Dislocations

The incidence of dislocation was measured in 7 trials enrolling 1296 patients (CHA, 656; UCHA, 640). There was no significant difference between the CHA and UCHA groups.

Heterotopic ossification

The pooled analysis found no heterogeneity, and there was no difference within groups.

Acetabular erosion

The results showed no difference between the two groups.

\section{General complications}

Wound Infection

Data regarding wound infection were reported by 13 studies in 2193 patients (1104 vs 1089). No significant difference was detected (RR=1.068, $P=0.781)$.

Pneumonia

Eleven studies reported pneumonia in 1935 patients ( 975 vs 960). The results showed no significant difference between the 2 groups (RR=0.799, $P=0.282$ ).

Cardiovascular Disease

We combined the mentioned symptoms, such as tachycardia, arrhythmia, myocardial infarction together as cardiovascular complications. And there was no significant difference between the two groups $(R R=1.278, P=0.324)$.

Urinary Tract Infection

Seven articles considered urinary tract infections and investigated 812 patients (409 vs 403). No significant difference was found between the groups (RR=1.087, $\mathrm{P}=0.683$ ).

Pain (Visual analogue scale, VAS)

Six studies showed that CHA has lower VAS(WMD $=-0.568, \mathrm{P}=0.001)$.

Deep Vein Thrombosis

Five included articles reported deep vein thrombosis in 1174 patients (598 vs 576). There was no significant difference between the two groups (RR=1.050, $\mathrm{P}=0.910)$.

Pressure Injury

Five trials reported pressure injury in 1069 patients (530 vs 529). The results showed that UCHA carried a higher risk of pressure injury event (RR=0.432, $\mathrm{P}=0.014)$.

Pulmonary Embolism

Five trials reported pulmonary embolism in 1160 patients (590 vs 570). The rate of pulmonary embolism was higher in CHA group but the difference was not significant $(R R=2.556, P=0.063)$.

Renal Failure

Renal failure was measured in 4 enrolled studies. The result suggested that there was no difference (RR= 0.972, $P=0.954)$.

Gastric Bleeding

Four studies provided information on gastric bleeding. The limited data showed no significant difference $(R R=1.382, P=0.614)$.

Page 4/16 
Hematoma

No significant difference was found regarding hematoma ( $R R=1.836, P=0.287)$.

Mental Status Change

No significant difference was found $(R R=0.862, P=0.476)$.

\section{Operative Outcomes}

Surgery Length

Nineteen studies reported the operative duration. It was longer in the CHA group (WMD=8.739, $\mathrm{P}<0.00001)$.

Blood loss

This parameter was measured by 15 studies in 2277 people (CHA, 1142; UCHA, 1135). There was no significant difference(WMD=26.218mL, $\mathrm{P}=0.085)$, but the results should be considered carefully due to the high heterogeneity $\left(P<0.0001, \mathrm{I}^{2}=80.4 \%\right)$.

Hospital Length

The length of hospital stay was described by 10 studies including 1450 patients. CHA has shorter overall length of hospital stay, although there was no significant difference(WMD=-0.330, $\mathrm{P}=0.279)$.

Blood Transfusion

The pooled effect of 6 RCTs $(n=1682)$ did not favour either of the two groups in terms of blood transfusion (RR=1.000, $P=0.999)$.

\section{Mortality}

The results showed no significant differences between the CHA and UCHA groups for mortality within, within 6 months, and after 2 years. However, the mortality was slightly higher at one year in UCHA group.

\section{Discussion}

Hip function

Barenius[17] found hip function recovery was better in the CHA group in the short term but it deteriorated over time, with no statistically significant difference at 48 months. Khorami[24] and Li[39] described the HHS grade with no specific numbers, so we excluded their data. Taylor[36] used the Oxford hip score (OHS) to assess hip function and concluded that the results were poorer in the UCHA group at 6 weeks, which is in agreement with the result reported by Singh[33]. The OHS is a validated instrument for assessing the outcome of hip replacement based on patient perception in terms of hip pain and function. Since the grouping is arbitrary and is not suggested by the originators of the OHS, we did not synthesize the data from studies using these instruments. DeAngelis[18] collected information about hip function using the Instrumental Activities of Daily Living and Physical Activities of Daily Living scales and the Energy/Fatigue Scale Instruments. The results showed no statistically significant difference in functional outcomes[18]. Parker[15] measured each patient's walking ability using a mobility scale adapted from a hip fracture mobility score and found that patients in the $\mathrm{CHA}$ group regained a better degree of mobility at 1 year. His study, performed 10 years ago, also found better scores for 3 of 16 activities of daily living in the CHA group[29]. Moroni's[28] study is different from most other studies, and we found that one possible reason may be that the implants he used were Furlong prostheses coated with HA. The outcomes obtained with the Furlong prosthesis may be due to the advantages of the HA coating in binding with osteoporotic bone, thus establishing stable fixation in patients[28]. Santini[31] used the total functional score (ranging from 0 to 18 points) to evaluate walking ability and personal daily activity. There was no difference regarding the total functional score[31]. Sonne-holm[40] assessed hip function according to pain, gait function, and hip mobility on a scale of 0-6. CHA yielded significantly better results at 3 and 6 months, but after 1 year, approximately $40 \%$ of all patients had normal gait function. Emery and Dorr also described similar results in that patients treated with CHA showed a better ability to walk[20,19]. Due to the loss of patients over the long follow-up in Lanslet's study, their results showing that the HHS favoured the uncemented group should be interpreted cautiously[25].

It was difficult to pool data from previous studies due to the inconsistency of the outcome parameters. Therefore, we used the HHS score as a standard parameter with a large sample and confirmed that CHA led to better hip function up to 12 months, with no difference thereafter. The reason may be that bone cement forms a solid bond between the stem and bone, providing favourable biomechanical advantages, further reducing the degree of early postoperative pain, and leading to better mobility and early mobilization. Limited long-term follow-up trials were included in our analysis, and we suggest that future studies should enrol more long-term follow-up trials.

Prothesis-related complications

The increased occurrence of prosthesis-related complications is highly suspected as the reasons for the greater pain and inferior hip function recovery in UCHA, generating a vicious cycle of worse outcomes in patients. Large database as reports from the Norwegian hip fracture register show a doubling need for secondary surgery in UCHA. Our study is in favour of previous registry outcomes and found that the rates of refracture, loosening or subsidence, and revision were obviously lower in the CHA group. 
According to Vidovic, one of the possible reasons for these results may be that patients in CHA group get improved function and weight-bearing (higher HHS) and can promote bone formation thus had lower periprosthetic bone loss[37]. Another reason for prosthesis-related complications is more in CHA may be that when surgeons use press-fitting to place uncemented stems, accidental fracture during insertion or broaching can occur. Some new uncemented stems have been used in several studies and proven to yield better results. Song[41] pointed out that higher refracture rates are associated with the use of modern uncemented stems compared to cemented stems in FNF. These complications still exist despite the evolving designs and materials[10]. Our results also supported these points.

We recommend that new materials should be considered in combination with patients' conditions, such as canals or bone quality. Technically, the procedure should yield tight contact between the prosthesis and the endosteal bone surface through careful steps during the surgery and without the use of brutal force.

Common complications

Pressure Injury

A significant difference was revealed regarding pressure injury, which was not found by previous studies. This suggests that our meta-analysis achieved greater power in detecting significant differences. Interestingly, cardiovascular complications were similar between groups in our study, which is contrary to the widely accepted view that $\mathrm{CHA}$ is associated with higher vascular complications. This may be explained by the prevailing idea of enhanced recovery after surgery and the large number of surgeons who are now mobilizing patients early.

Our study shows that pneumonia and urinary tract infection occurred less frequently in the CHA group, with no statistically significant difference. This is consistent with Yoon's[42] conclusion. This may be due to early ambulation or early urinary catheter removal in the CHA group[42].

Pain

Postoperative pain may hinder patients from weight-bearing, disturbing bone mass recovery and function regain [37]. In previous studies, pain was less common in the CHA group, but the incidence differed [15,12]. Of the 24 included RCTs, some recorded patients with pain or without pain; some used the visual analogue scale (VAS) score or the HHS pain sub-score to evaluate pain. After pooling the data, we found lower VAS score in the CHA group.

Operative outcomes

Our results demonstrate that $\mathrm{CHA}$ was associated with a significantly prolonged operative duration (WMD $=8.739 \mathrm{minutes}, \mathrm{p}<0.0001)$, which is consistent with the results of other studies. This finding is probably partly due to the waiting periods required for cement polymerization, insertion and solidification.

There was no difference in the volume of blood loss or the length of hospital stay. These results may be due to earlier mobilization after CHA than UCHA, thus reducing the hospital time. However, it is not clear whether these patients still go to nursing homes or other rehabilitation facilities for recovery, and the lack of recorded data may cause confusion. However, due to the ways used in different areas in measuring blood loss, we can not analysis the high heterogeneity and the results should be explained carefully. What should be noted is that the blood transfusion requirement is similar within groups, and it remind us it may be less important to care for the intraoperative blood loss.

Mortality

Whether CHA has a higher mortality rate than UCHA has long been debated. Kumar[8] reported that CHA had higher 1-year mortality, while Kristensen[6] showed that there was no difference. Our study shows that the mortality rate lower at 1 year postoperatively in CHA group, which is consistent with mainstream previous reports[5,7,43].

CHA can lead to death due to bone cement implantation syndrome (BCIS), which occurs at a rate of approximately $0.5 \% \sim 0.6 \%[15]$. The latest RCT reported 3 deaths that may have been caused by BCIS [15], and Moerman also reported one death possible caused by it[26]. Similar events have been reported by other trials, as well as Australian joint replacement registry[23,21,44]. Movrin[16] noted that there were 8 (10.1\%) events of an intraoperative drop in the oxygen saturation (SaO2) in the CHA group, which may have been the reason for BCIS. In a cohort study, Costain[45] et al found a significant difference in the one-day mortality rate, at $0.5 \%$ in the UCHA group and $0.8 \%$ in the CHA group $(p<0.001)$ [8]. Two large studies of over 20,000 patients each showed that perioperative death was significantly increased in $\mathrm{CHA}$ due to $\mathrm{BCIS}[46,47]$. Regarding long-term effects, Ekman holds the view that greater mortality in the longer term after $\mathrm{CHA}$ is related to comorbidities[43]. Both surgeons and anaesthesiologists should consider patients' intraoperative blood pressure and oxygen saturation. Thus, we suggest that surgeons determine the best type of surgical procedure based on each patient's own conditions, including physiology, morbidities and cardiovascular condition and follow the guidelines of management of BCIS.

\section{Conclusions}

This meta-analysis demonstrates that CHA has better hip function, lower rates of refracture, subsidence or loosening, revision, VAS scores, pressure injury event and one-year mortality than UCHA; UCHA had shorter operative duration.

We believe we are by far the first study enrolled the largest number of RCTs and included the most details of modern implants and traditional ones. We firmly believe our conclusion is stable and reliable.

Our study also has several limitations. We did not exclude studies based on criteria such as the implant type (e.g., unipolar or bipolar), patient age, or stem design (e.g., modern or traditional). The latter makes our study generalizable to all elderly patients treated with hemiarthroplasty. 


\section{List Of Abbreviations}

RCTs: Randomized controlled trials; CHA: Cemented hemiarthroplasty; UCHA: Uncemented hemiarthroplasty; FNF: Femoral neck fracture; WMD: Weight mean deviation; Cl: Confidence interval; RR: Risk ratio; HHS: Harris hip score; VAS: Visual analogue scale; OHS: Oxford hip score; Bone cement implantation syndrome: BCIS

\section{Declarations}

\section{Ethics approval and consent to participate}

This meta-analysis and all the included studies meet all the ethical standards described in the declaration of Helsinki. No ethical committee approval was required for this study.

\section{Consent for publication}

All authors have stated for consents of publications.

\section{Availability of data and materials}

The datasets used and analysed during the current study are available from the corresponding author on reasonable request.

\section{Competing interests}

The authors declare no competing interests.

\section{Funding}

No funding was available for this study.

\section{Authors' contributions}

TXM conceived the methods of the study, performed the database search, the article selection and data extraction processes, performed the statistical analysis and drafted the manuscript. WD conceived the methods of the study, performed the database search, the article selection and data extraction processes, and drafted the manuscript. NN conceived the methods of the study, helped with the data extraction process, and drafted the manuscript. LY, CJL, LPF, and ZZZ helped to draft the manuscript. All authors read and approved the manuscript.

\section{Acknowledgements}

Not applicable

\section{References}

1. Gullberg B, Johnell O, Kanis JA (1997) World-wide projections for hip fracture. Osteoporosis International 7 (5):407-413. doi:10.1007/pl00004148

2. Foss NB, Kehlet $\mathrm{H}$ (2005) Mortality analysis in hip fracture patients: implications for design of future outcome trials. $\mathrm{Br} \mathrm{J}$ Anaesth 94 (1):24-29. doi:10.1093/bja/aei010

3. Hernlund E, Svedbom A, Ivergard M, Compston J, Cooper C, Stenmark J, McCloskey EV, Jonsson B, Kanis JA (2013) Osteoporosis in the European Union: medical management, epidemiology and economic burden. Archives of Osteoporosis 8 (1-2). doi:10.1007/s11657-013-0136-1

4. Hansson S, Bulow E, Garland A, Karrholm J, Rogmark C (2020) More hip complications after total hip arthroplasty than after hemi-arthroplasty as hip fracture treatment: analysis of 5,815 matched pairs in the Swedish Hip Arthroplasty Register. Acta orthopaedica 91 (2):133-138. doi:10.1080/17453674.2019.1690339

5. Alisi MS, Al-Alajlouni J, Hammad Y, Mousa K, Elifranji Z, Alaqrabawi I, Al-Saber M, Alsousi A, Elessi K (2020) Management of hip fractures among elderly patients at Jordan University Hospital: A cross-sectional study. Current Orthopaedic Practice 31 (3):231-239. doi:10.1097/bco.0000000000000862

6. Kristensen TB, Dybvik E, Kristoffersen M, Dale H, Engesaeter LB, Furnes O, Gjertsen JE (2020) Cemented or Uncemented Hemiarthroplasty for Femoral Neck Fracture? Data from the Norwegian Hip Fracture Register. Clin Orthop Relat Res 478 (1):90-100. doi:10.1097/corr.0000000000000826

7. Lin FF, Chen YF, Chen B, Lin CH, Zheng K (2019) Cemented versus uncemented hemiarthroplasty for displaced femoral neck fractures: A meta-analysis of randomized controlled trails. Medicine 98 (8):e14634. doi:10.1097/md.0000000000014634

8. Kumar P, Rajnish RK, Neradi D, Kumar V, Agarwal S, Aggarwal S (2019) Hemiarthroplasty for neck of femur fractures: to cement or not? A systematic review of literature and meta-analysis. European journal of orthopaedic surgery \& traumatology : orthopedie traumatologie 29 (4):731-746. doi:10.1007/s00590-019-02364-z

9. Imam MA, Shehata MSA, Elsehili A, Morsi M, Martin A, Shawqi M, Grubhofer F, Chirodian N, Narvani A, Ernstbrunner L (2019) Contemporary cemented versus uncemented hemiarthroplasty for the treatment of displaced intracapsular hip fractures: a meta-analysis of forty-two thousand forty-six hips. International orthopaedics 43 (7):1715-1723. doi:10.1007/s00264-019-04325-x

10. Veldman HD, Heyligers IC, Grimm B, Boymans TA (2017) Cemented versus cementless hemiarthroplasty for a displaced fracture of the femoral neck: a systematic review and meta-analysis of current generation hip stems. Bone Joint J 99-b (4):421-431. doi:10.1302/0301-620x.99b4.Bjj-2016-0758.R1 
11. Ning GZ, Li YL, Wu Q, Feng SQ, Li Y, Wu QL (2014) Cemented versus uncemented hemiarthroplasty for displaced femoral neck fractures: an updated metaanalysis. European journal of orthopaedic surgery \& traumatology : orthopedie traumatologie 24 (1):7-14. doi:10.1007/s00590-012-1151-4

12. Li T, Zhuang Q, Weng X, Zhou L, Bian Y (2013) Cemented versus uncemented hemiarthroplasty for femoral neck fractures in elderly patients: a metaanalysis. PloS one 8 (7):e68903. doi:10.1371/journal.pone.0068903

13. Ahn J, Man LX, Park S, Sodl JF, Esterhai JL (2008) Systematic review of cemented and uncemented hemiarthroplasty outcomes for femoral neck fractures. Clin Orthop Relat Res 466 (10):2513-2518. doi:10.1007/s11999-008-0368-3

14. Li N, Zhong L, Wang C, Xu M, Li W (2020) Cemented versus uncemented hemi-arthroplasty for femoral neck fractures in elderly patients: A systematic review and meta-analysis of randomized controlled trials. Medicine 99 (8):e19039. doi:10.1097/md.0000000000019039

15. Parker MJ, Cawley S (2020) Cemented or uncemented hemiarthroplasty for displaced intracapsular fractures of the hip: a randomized trial of 400 patients. Bone Joint J 102-b (1):11-16. doi:10.1302/0301-620x.102b1.Bjj-2019-1041.R1

16. Movrin I (2020) Cemented versus uncemented hemiarthroplasty for displaced femoral neck fractures: A randomized controlled trial with two years followup. Acta orthopaedica et traumatologica turcica 54 (1):83-88. doi:10.5152/j.aott.2020.01.432

17. Barenius B, Inngul C, Alagic Z, Enocson A (2018) A randomized controlled trial of cemented versus cementless arthroplasty in patients with a displaced femoral neck fracture: a four-year follow-up. Bone Joint J 100-b (8):1087-1093. doi:10.1302/0301-620x.100b8.Bjj-2017-1593.R1

18. Deangelis JP, Ademi A, Staff I, Lewis CG (2012) Cemented versus uncemented hemiarthroplasty for displaced femoral neck fractures: a prospective randomized trial with early follow-up. Journal of orthopaedic trauma 26 (3):135-140. doi:10.1097/BOT.0b013e318238b7a5

19. Dorr LD, Glousman R, Hoy AL, Vanis R, Chandler R (1986) Treatment of femoral neck fractures with total hip replacement versus cemented and noncemented hemiarthroplasty. The Journal of arthroplasty 1 (1):21-28. doi:10.1016/s0883-5403(86)80006-7

20. Emery RJ, Broughton NS, Desai K, Bulstrode CJ, Thomas TL (1991) Bipolar hemiarthroplasty for subcapital fracture of the femoral neck. A prospective randomised trial of cemented Thompson and uncemented Moore stems. The Journal of bone and joint surgery British volume 73 (2):322-324

21. Figved W, Opland V, Frihagen F, Jervidalo T, Madsen JE, Nordsletten L (2009) Cemented versus Uncemented Hemiarthroplasty for Displaced Femoral Neck Fractures. Clinical Orthopaedics and Related Research 467 (9):2426-2435. doi:10.1007/s11999-008-0672-y

22. Hongpu Z (2012) Cement and non-cement dual cups in the treatment of femoral neck fractures in the elderly. Orthopedic Journal of China 20 (12)

23. Inngul C, Blomfeldt R, Ponzer S, Enocson A (2015) Cemented versus uncemented arthroplasty in patients with a displaced fracture of the femoral neck: a randomised controlled trial. The bone \& joint journal 97-B (11):1475-1480. doi:10.1302/0301-620X.97B11.36248

24. Khorami M, Arti H, Aghdam AA (2016) Cemented versus uncemented hemiarthroplasty in patients with displaced femoral neck fractures. Pak J Med Sci 32 (1):44-48. doi:10.12669/pjms.321.8461

25. Langslet E, Frihagen F, Opland V, Madsen JE, Nordsletten L, Figved W (2014) Cemented versus uncemented hemiarthroplasty for displaced femoral neck fractures: 5-year followup of a randomized trial. Clin Orthop Relat Res 472 (4):1291-1299. doi:10.1007/s11999-013-3308-9

26. Moerman S, Mathijssen NMC, Niesten DD, Riedijk R, Rijnberg WJ, Koeter S, Kremers van de Hei K, Tuinebreier WE, Molenaar TL, Nelissen R, Vochteloo AJH (2017) More complications in uncemented compared to cemented hemiarthroplasty for displaced femoral neck fractures: a randomized controlled trial of 201 patients, with one year follow-up. BMC musculoskeletal disorders 18 (1)

27. Mohabey AV, Warjukar PR, Ravikumar M (2017) Functional outcome of cemented versus uncemented modular bipolar hemiarthroplasty in proximal femoral neck fractures. International Journal of Orthopaedics Sciences 3 (4i):609-611. doi:10.22271/ortho.2017.v3.i4i.83

28. Moroni A, Pegreffi F, Romagnoli M, Hoang-Kim A, Tesei F, Giannini S (2009) Results in osteoporotic femoral neck fractures treated with cemented vs uncemented hip arthroplasty. Journal of bone and joint surgery - british volume 91-B (SUPP_I):167

29. Parker MI, Pryor G, Gurusamy K (2010) Cemented versus uncemented hemiarthroplasty for intracapsular hip fractures: A randomised controlled trial in 400 patients. The Journal of bone and joint surgery British volume 92 (1):116-122. doi:10.1302/0301-620x.92b1.22753

30. Qi G (2017) Contrast of effect and prognosis of artificial hip joint maken by biomaterials and bone-cement for femoral neck fracture. Orthopaedic Biomechanics Materials and Clinical Study 14 (01):53-55+60. doi:10.3969/j.issn.1672.2017.01.014

31. Santini S, Rebeccato A, Bolgan I, Turi G (2005) Hip fractures in elderly patients treated with bipolar hemiarthroplasty: comparison between cemented and cementless implants. Journal of orthopaedics and traumatology $6(2): 80-87$

32. Shenqi P (2013) Comparison of the efficacy of bone cement type and non-bone cement type hemihip replacement for displaced femoral neck fracture. Chinese Journal of Postgraduates of Medicine 36 (17):41-43. doi:10.3760/cma.j.issn.1673-4904.2013.17.015

33. Singh GK, Deshmukh RG (2006) Uncemented Austin-Moore and cemented Thompson unipolar hemiarthroplasty for displaced fracture neck of femurcomparison of complications and patient satisfaction. Injury 37 (2):169-174. doi:10.1016/j.injury.2005.09.016

34. Sonne-Holm S, Walter S, Jensen JS (1982) Moore hemi-arthroplasty with and without bone cement in femoral neck fractures. A clinical controlled trial. Acta orthopaedica Scandinavica 53 (6):953-956. doi:10.3109/17453678208992854

35. Talsnes O, Hjelmstedt F, Pripp AH, Reikerås O, Dahl OE (2013) No difference in mortality between cemented and uncemented hemiprosthesis for elderly patients with cervical hip fracture. A prospective randomized study on 334 patients over 75 years. Archives of orthopaedic and trauma surgery 133 (6):805-809. doi:10.1007/s00402-013-1726-5

36. Taylor F, Wright M, Zhu M (2012) Hemiarthroplasty of the hip with and without cement: a randomized clinical trial. Journal of bone and joint surgery American volume 94 (7):577-583. doi:10.2106/JBJS.K.00006

37. Vidovic D, Punda M, Darabos N, Bekavac-Beslin M, Bakota B, Matejcic A (2015) Regional bone loss following femoral neck fracture: A comparison between cemented and cementless hemiarthroplasty. Injury 46 Suppl 6:S52-56. doi:10.1016/j.injury.2015.10.069 
38. Xingwang L (2017) Comparison of the efficacy of cement and non-cement bone in the treatment of femoral neck fractures in the elderly. Contemporary Medicine 23 (No.464). doi:doi:10.3969/j.

39. Jianguo $L$ (2017) comparison of the effects and complications $f$ biotype and cement-based artificial hip prsthesis in the treatment of femoral neck fracture in the elderly. Clinical Medicine of China 33 (12)

40. Sonne-Holm S, Walter S, Jensen JS (1982) Moore hemi-arthroplasty with and without bone cement in femoral neck fractures. A clinical controlled trial. Acta orthopaedica Scandinavica 53 (6):953-956

41. Song JSA, Dillman D, Wilson D, Dunbar M, Richardson G (2019) Higher periprosthetic fracture rate associated with use of modern uncemented stems compared to cemented stems in femoral neck fractures. Hip international : the journal of clinical and experimental research on hip pathology and therapy 29 (2):177-183. doi:10.1177/1120700018772291

42. Yoon BH, Seo JG, Koo KH (2017) Comparison of Postoperative Infection-Related Complications between Cemented and Cementless Hemiarthroplasty in Elderly Patients: A Meta-Analysis. Clin Orthop Surg 9 (2):145-152. doi:10.4055/cios.2017.9.2.145

43. Ekman E, Laaksonen I, Isotalo K, Liukas A, Vahlberg T, Makela K (2019) Cementing does not increase the immediate postoperative risk of death after total hip arthroplasty or hemiarthroplasty: a hospital-based study of 10,677 patients. Acta orthopaedica 90 (3):270-274. doi:10.1080/17453674.2019.1596576

44. Kristensen T, Dybvik E, Kristoffersen M, Engesaeter L, Furnes O, Gjertsen J-E (2019) Cemented or Uncemented Hemiarthroplasty for Femoral Neck Fracture? Data from the Norwegian Hip Fracture Register. Clinical Orthopaedics and Related Research 478. doi:10.1097/CORR.0000000000000826

45. Costain DJ, Whitehouse SL, Pratt NL, Graves SE, Ryan P, Crawford RW (2011) Perioperative mortality after hemiarthroplasty related to fixation method. Acta orthopaedica 82 (3):275-281. doi:10.3109/17453674.2011.584208

46. Costain DJ, Whitehouse SL, Pratt NL, Graves SE, Ryan P, Crawford RW (2011) Perioperative mortality after hemiarthroplasty related to fixation method. Acta orthopaedica 82 (3):275-281. doi:10.3109/17453674.2011.584208

47. Middleton R, Uzoigwe C, Young P, Smith R, Gosal H, Holt G (2014) Peri-operative mortality after hemiarthroplasty for fracture of the hip DOES CEMENT MAKE A DIFFERENCE? The bone \& joint journal 96-B:1185-1191. doi:10.1302/0301-620X.96B9.33935

\section{Tables}

\section{Table 1 Characteristics of the included studies}




\begin{tabular}{|c|c|c|c|c|c|c|c|c|c|}
\hline Studies & Period & $\begin{array}{l}\text { Age } \\
\text { CH/UCHA }\end{array}$ & $\begin{array}{l}\text { Gender } \\
\text { male/female }\end{array}$ & $\begin{array}{l}\text { Bipolar/ } \\
\text { unipolar }\end{array}$ & $\begin{array}{l}\text { Number } \\
\text { CH/UCHA }\end{array}$ & $\begin{array}{l}\text { ASA } \\
(1,2 / 3,4) \\
\text { (Mean } \\
\text { Score) }\end{array}$ & Surgeon & \multicolumn{2}{|c|}{$\begin{array}{l}\text { Implants type } \\
\text { CH/UCHA }\end{array}$} \\
\hline $\begin{array}{l}\text { Barenius2018 } \\
\text { [3] }\end{array}$ & $\begin{array}{l}2009.10- \\
2013.04\end{array}$ & $81.2(8.95) / 81.3(7.81)$ & $41 / 99$ & a & $67 / 74$ & $67 / 141$ & $\begin{array}{l}14 \text { OS } \\
\text { (Experienced) }\end{array}$ & $\begin{array}{l}\text { Cemer } \\
\text { stem }{ }^{1} \\
\text { Hydro> } \\
\text { stem }^{2}\end{array}$ & $\begin{array}{l}\text { ed Unipolar Exetel } \\
\text { ncemented Unipc } \\
\text { apatite-coated Bi }\end{array}$ \\
\hline $\begin{array}{l}\text { DeAngelis2012 } \\
{[5]}\end{array}$ & $\begin{array}{l}2005.03- \\
2008.05\end{array}$ & $\begin{array}{l}81.8(9.0) / \\
82.8(7.6)\end{array}$ & $30 / 100$ & $\mathrm{a}$ & $66 / 64$ & $110 / 20$ & $\begin{array}{l}\text { OS } \\
\text { (Attending) }\end{array}$ & $\begin{array}{l}\text { Cemer } \\
\text { Prosth } \\
\text { Unipol }\end{array}$ & $\begin{array}{l}\text { ed Unipolar Femo } \\
\text { sis }^{3} / \text { Uncemented } \\
\text { Component }^{4}\end{array}$ \\
\hline $\begin{array}{l}\text { Dorr1986 } \\
\text { [6] }\end{array}$ & $\begin{array}{l}1980.03- \\
1982.07\end{array}$ & $\begin{array}{l}\text { 72ه10.390/ } \\
66(12.73)\end{array}$ & $15 / 35$ & $\mathrm{~b}$ & $37 / 13$ & $\mathrm{~N} / \mathrm{A}$ & $\mathrm{N} / \mathrm{A}$ & $\mathrm{N} / \mathrm{A}$ & \\
\hline $\begin{array}{l}\text { Emery1991 } \\
{[8]}\end{array}$ & unclear & $\begin{array}{l}78(7.2) / \\
79.6(8)\end{array}$ & $7 / 46$ & $b$ & $27 / 26$ & $\mathrm{~N} / \mathrm{A}$ & $\begin{array}{l}\text { Junior OS } \\
\text { (Same } \\
\text { group) }\end{array}$ & Thom & on $^{5}$ /Austin Mool \\
\hline $\begin{array}{l}\text { Figved2009 } \\
\text { [9] }\end{array}$ & $\begin{array}{l}\text { 2004.09- } \\
2006.08\end{array}$ & $83.4(5.68) / 83.0(6.29)$ & $53 / 167$ & $b$ & $112 / 108$ & $94 / 126$ & os & Spectr & $\mathrm{TM}^{6} /$ Corail-1 $^{7}$ \\
\hline $\begin{array}{l}\text { Guo2017 } \\
\text { [33] }\end{array}$ & $\begin{array}{l}2010.06- \\
2014.12\end{array}$ & $\begin{array}{l}66.2(15.8) / \\
68.7(16.8)\end{array}$ & $59 / 41$ & $\mathrm{~N} / \mathrm{A}$ & $50 / 50$ & $\mathrm{~N} / \mathrm{A}$ & $\mathrm{N} / \mathrm{A}$ & $\mathrm{N} / \mathrm{A}$ & \\
\hline $\begin{array}{l}\text { Inngul2015 } \\
{[16]}\end{array}$ & $\begin{array}{l}2009.10- \\
2013.04\end{array}$ & $81.2(8.95) / 81.3(7.81)$ & $41 / 99$ & $\mathrm{a}$ & $67 / 74$ & $67 / 141$ & $\begin{array}{l}14 \text { OS } \\
\text { (Experienced) }\end{array}$ & $\begin{array}{l}\text { Cemer } \\
\text { stem }{ }^{1} \\
\text { Hydro> } \\
\text { stem }^{2}\end{array}$ & $\begin{array}{l}\text { ed Unipolar Exetel } \\
\text { ncemented Unipc } \\
\text { apatite-coated Bi }\end{array}$ \\
\hline Khorami2016[18] & $\begin{array}{l}2011- \\
2012\end{array}$ & $79(6.38) / 71.7(3.19)$ & $19 / 32$ & $\mathrm{~b}$ & $22 / 29$ & $\mathrm{~N} / \mathrm{A}$ & os & Bipola & Zimmer femoral \\
\hline $\begin{array}{l}\text { Langslet2014 } \\
{[21]}\end{array}$ & $\begin{array}{l}\text { 2004.09- } \\
2006.08\end{array}$ & $83.4(5.68) / 83.0(6.29)$ & $53 / 167$ & $\mathrm{~b}$ & $112 / 108$ & $94 / 126$ & os & Spectr & $\mathrm{TM}^{6} /$ Corail-1 $^{7}$ \\
\hline $\begin{array}{l}\text { Li2017 } \\
\text { [17] }\end{array}$ & $\begin{array}{l}2013.10- \\
2015.10\end{array}$ & $\begin{array}{l}70.2(2.4) / \\
69.6(2.2)\end{array}$ & $36 / 79$ & $\mathrm{~N} / \mathrm{A}$ & $40 / 39$ & $\mathrm{~N} / \mathrm{A}$ & $\mathrm{N} / \mathrm{A}$ & & $\mathrm{N} / \mathrm{A}$ \\
\hline $\begin{array}{l}\text { Moerman2017 } \\
{[25]}\end{array}$ & $\begin{array}{l}2008.08- \\
2012.06\end{array}$ & $84(6.7) / 83(6.2)$ & $58 / 143$ & $\mathrm{a}$ & $110 / 91$ & $135 / 66$ & $\begin{array}{l}\text { Orthopedic } \\
\text { surgeon/Regis }\end{array}$ & & $\begin{array}{l}\text { Cemented Müllı } \\
\text { Straight } \\
\text { Stem }{ }^{8} / \text { Unceme } \\
\text { DB- } 10^{9}\end{array}$ \\
\hline $\begin{array}{l}\text { Mohabey2017 } \\
{[26]}\end{array}$ & $\begin{array}{l}\text { 2014.09- } \\
2015.12\end{array}$ & 70.03(11.55) & $18 / 22$ & $b$ & $20 / 20$ & $\mathrm{~N} / \mathrm{A}$ & $\mathrm{N} / \mathrm{A}$ & & $\begin{array}{l}\text { Cemented } \\
\text { modular/Uncen } \\
\text { modular bipolaı }\end{array}$ \\
\hline $\begin{array}{l}\text { Moroni2018 } \\
\text { [27] }\end{array}$ & $\mathrm{N} / \mathrm{A}$ & $75(5)$ & $0 / 40$ & a & $22 / 18$ & $\mathrm{~N} / \mathrm{A}$ & os & & $\begin{array}{l}\text { AHS prosthesis } \\
\text { coated Furlong } \\
\text { prosthesis }\end{array}$ \\
\hline $\begin{array}{l}\text { Movrin2020 } \\
\text { [28] }\end{array}$ & $\begin{array}{l}\text { 2013.01- } \\
2015.12\end{array}$ & $\begin{array}{l}86(5) / \\
84(4)\end{array}$ & $64 / 94$ & $\mathrm{~b}$ & $79 / 79$ & $86 / 72$ & $\begin{array}{l}9 \\
\text { consultants/sp } \\
\text { orthopedic trau } \\
\text { surgeons }\end{array}$ & $\begin{array}{l}\text { ecialist } \\
\text { na }\end{array}$ & $\begin{array}{l}\text { modular bipolaı } \\
\text { prosthesis, 80-n } \\
\text { Palacos cemen } \\
\text { uncemented mc } \\
\text { bipolar }\end{array}$ \\
\hline $\begin{array}{l}\text { Parker2020 } \\
\text { [31] }\end{array}$ & $\begin{array}{l}2013.08- \\
2018.06\end{array}$ & $\begin{array}{l}77.1(8.4) / \\
77.1(6.35)\end{array}$ & $127 / 277$ & a & $200 / 200$ & $71 / 329$ & $\begin{array}{l}\text { Lead trialist } \\
\text { (MJP) }\end{array}$ & & $\begin{array}{l}\text { cemented unipc } \\
\text { double-tapered } \\
\text { stem }{ }^{11} \text { Biomet/ } \\
\text { uncemented ful } \\
\text { hydroxyapatite- } \\
\text { coated Furlong }\end{array}$ \\
\hline $\begin{array}{l}\text { Parker2010 } \\
{[30]}\end{array}$ & $\begin{array}{l}\text { 2001.03- } \\
2006.11\end{array}$ & $\begin{array}{l}83(10.46) / \\
83(12.12)\end{array}$ & $92 / 308$ & a & $200 / 200$ & $2.7 / 2.7$ & 1 OS & & $\begin{array}{l}\text { Thompson }{ }^{13} / \mathrm{A} \\
\text { Moore }^{14}\end{array}$ \\
\hline $\begin{array}{l}\text { Pan2013 } \\
{[35]}\end{array}$ & $\begin{array}{l}2005.10- \\
2011.10\end{array}$ & $\begin{array}{l}70.5(5.5) / \\
72.2(7.6)\end{array}$ & $19 / 61$ & $\mathrm{~N} / \mathrm{A}$ & $41 / 39$ & $\mathrm{~N} / \mathrm{A}$ & os & & $\mathrm{N} / \mathrm{A}$ \\
\hline Singh2005 & 1999.01- & $84 / 83$ & $8 / 46$ & a & $25 / 29$ & $\mathrm{~N} / \mathrm{A}$ & consultant OS & & Thompson/Aus \\
\hline
\end{tabular}

Page 10/16 


\begin{tabular}{|c|c|c|c|c|c|c|c|c|}
\hline [36] & 2000.12 & & & & & & $\begin{array}{l}\text { middle grade OS/ } \\
\text { SHO }\end{array}$ & Moore \\
\hline $\begin{array}{l}\text { Santini2005 } \\
{[34]}\end{array}$ & $\begin{array}{l}2000.09- \\
2001.12\end{array}$ & $\begin{array}{l}82.09(7.60) / \\
79.68(8.62)\end{array}$ & $60 / 46$ & $b$ & $53 / 53$ & $11 / 105$ & N/A & $\mathrm{N} / \mathrm{A}$ \\
\hline $\begin{array}{l}\text { Sonne- } \\
\text { Holm1982 } \\
{[38]}\end{array}$ & 1979 & $\mathrm{~N} / \mathrm{A}$ & $37 / 75$ & $\mathrm{~N} / \mathrm{A}$ & $55 / 57$ & $\mathrm{~N} / \mathrm{A}$ & $\mathrm{N} / \mathrm{A}$ & $\begin{array}{l}\text { Moore cemente } \\
\text { methyl-methacr } \\
\text { Moore uncemer } \\
\text { prosthesis }\end{array}$ \\
\hline $\begin{array}{l}\text { Talsnes2013 } \\
\text { [40] }\end{array}$ & $\begin{array}{l}2005- \\
2010\end{array}$ & $84.0(5.1) / 84.3(5.0)$ & $82 / 252$ & $\mathrm{~N} / \mathrm{A}$ & $162 / 172$ & $138 / 196$ & N/A & $\begin{array}{l}\text { bipolar cement } \epsilon \\
\text { bipolar non- } \\
\text { cemented }^{16}\end{array}$ \\
\hline $\begin{array}{l}\text { Taylor2013 } \\
\text { [41] }\end{array}$ & $\begin{array}{l}2006.05- \\
2008.11\end{array}$ & $85.3(7) / 85.1(6.6)$ & $50 / 110$ & a & $80 / 80$ & N/A & consultant OS & $\begin{array}{l}\text { Cemented modular } \\
\text { stem with an } \\
\text { appropriately sized } \\
\text { UniTrax head } \\
\text { (Stryker)/uncement } \\
\text { Alloclassic stem wi1 } \\
\text { appropriately sized }\end{array}$ \\
\hline $\begin{array}{l}\text { Vidovic2013 } \\
{[43]}\end{array}$ & $\begin{array}{l}2007.01- \\
2010.12\end{array}$ & $82.9(4.63) / 82.04(4.32)$ & $0 / 79$ & a & $38 / 41$ & N/A & $\begin{array}{l}5 \mathrm{OS} \\
\text { (Experienced) }\end{array}$ & $\begin{array}{l}\text { Cemented } \\
\text { Modular/Cementles } \\
\text { Modular Austin Mor }\end{array}$ \\
\hline $\begin{array}{l}\text { Zhao2012 } \\
{[14]}\end{array}$ & $\begin{array}{l}\text { 2008.07- } \\
2011.06\end{array}$ & $77.03(5.17) / 76.34(5.62)$ & $40 / 91$ & $b$ & $67 / 64$ & N/A & 1 OS group & $\mathrm{N} / \mathrm{A}$ \\
\hline
\end{tabular}
a. Unipolar
b. Bipolar

N/A. not find

OS. orthopedic surgeon

DLA: direct lateral approach

SA: standard anterolateral approach

PA: Posterior approach

MPA: Modified posterolateral approach

HDLA: Hardinge direct lateral approach

1. Stryker, Kalamazoo, Michigan

2. Zimmer Biomet, Warsaw, Indiana

3. VerSys LD/Fx; Zimmer, Warsaw, IN

4. VerSys Beaded FullCoat; Zimmer, Warsaw, IN

5. Monk duoplet design (Johnson \& Johnson, England)

6. Smith \& Nephew, Inc, Memphis, TN

7. DePuy International Ltd, Leeds, UK

8. Zimmer - Biomet, 1800 West Center St. Warsaw, Indiana, USA

9. Zimmer- Biomet, 1800 West Center St. Warsaw, Indiana, USA

10. Heraeus, Wehrheim, Germany

11. Exeter Trauma Stem, Stryker Medical, Michigan, USA, or CPT Zimmer/Biomet, Warsaw, Indiana, USA

12. JRI Orthopaedics, Sheffield, UK

13. Stryker/Howmedica Ltd, Newbury, United Kingdom

14. Corin Ltd, Cirencester , United Kingdom

15. Landos Titan, Depuy, Warshaw, IN, USA

16. Landos Corail, Depuy, Warshaw, IN, USA 
Table 2 Outcomes of meta-analysis

Page 12/16 


\begin{tabular}{|c|c|c|c|c|c|c|c|}
\hline \multirow{2}{*}{ Variables } & \multirow{2}{*}{$\mathrm{N}$ (study) } & \multirow{2}{*}{$\mathrm{N}(\mathrm{CH})$} & \multirow{2}{*}{$\mathrm{N}(\mathrm{UCH})$} & \multicolumn{2}{|l|}{ Pooled data } & \multicolumn{2}{|c|}{ Heterogeneity } \\
\hline & & & & WMD/RR (95\% Cl) & $\mathrm{P}$ & $\mathrm{I}^{2}(\%)$ & $\mathrm{Ph}$ \\
\hline \multicolumn{8}{|l|}{ Hip Function(HHS) } \\
\hline HHS $₫<6$ week) & 2 & 122 & 126 & $9.097(3.034,15.161)$ & $<0.003^{\star}$ & $75.8 \%$ & 0.042 \\
\hline HHS $₫ 3$ months) & 5 & 291 & 282 & $3.347(1.478,5.216)$ & $<0.0001^{\star}$ & $45.5 \%$ & 0.119 \\
\hline HHS $₫ 6$ months) & 3 & 98 & 100 & $0.217(-5.860,6.294)$ & 0.944 & $91.9 \%$ & $<0.0001$ \\
\hline HHS $\unrhd 12$ month) & 7 & 375 & 375 & $2.183(0.161,4.205)$ & $0.034^{*}$ & $39.9 \%$ & 0.125 \\
\hline HHS $₫ 24$ to 60 months) & 4 & 156 & 186 & $0.337(-2.945,3.619)$ & 0.840 & $50.7 \%$ & 0.037 \\
\hline \multicolumn{8}{|c|}{ Prothesis-related Complications } \\
\hline Refracture & 9 & 910 & 898 & $0.227(0.135,0.381)$ & $<0.0001^{\star}$ & $0.00 \%$ & 0.941 \\
\hline Subsidence or Loosening & 9 & 485 & 467 & $0.295(0.112,0.778)$ & $<0.014^{*}$ & $49.30 \%$ & 0.061 \\
\hline Revision & 9 & 749 & 771 & $0.468(0.279,0.786)$ & $0.004^{*}$ & $0.00 \%$ & 0.781 \\
\hline Dislocation & 7 & 656 & 640 & $1.036(0.496,2.161)$ & 0.926 & $0.00 \%$ & 0.753 \\
\hline Heterotopic Ossification & 5 & 265 & 261 & $0.983(0.759,1.272)$ & 0.894 & 0.468 & $0.00 \%$ \\
\hline Acetabular Erosion & 3 & 189 & 205 & $1.769(0.400,7.831)$ & 0.452 & 0.229 & $32.10 \%$ \\
\hline \multicolumn{8}{|l|}{ General Complications } \\
\hline Wound Infection & 13 & 1104 & 1089 & $1.068(0.670,1.703)$ & 0.781 & 0.872 & $0.00 \%$ \\
\hline Pneumonia & 11 & 975 & 960 & $0.799(0.532,1.202)$ & 0.282 & 0.791 & $0.00 \%$ \\
\hline Cardiovascular Disease & 8 & 796 & 793 & $1.278(0.785,2.078)$ & 0.324 & 0.788 & $0.00 \%$ \\
\hline Urinary Tract Infection & 7 & 409 & 403 & $1.087(0.727,1.625)$ & 0.683 & 0.811 & $0.00 \%$ \\
\hline VAS & 6 & 520 & 525 & $-0.568(-0.897,-0.239)$ & $0.001 *$ & 0.017 & $63.6 \%$ \\
\hline Deep Vein Thrombosis & 5 & 598 & 576 & $1.050(0.452,2.439)$ & 0.910 & 0.876 & $0.00 \%$ \\
\hline Pressure Injury & 5 & 530 & 529 & $0.432(0.221,0.846)$ & $0.014^{\star}$ & 0.802 & $0.00 \%$ \\
\hline Pulmonary Embolism & 5 & 590 & 570 & $2.556(0.951,6.870)$ & 0.063 & 0.814 & $0.00 \%$ \\
\hline Renal Failure & 4 & 577 & 565 & $0.972(0.366,2.581)$ & 0.954 & 0.521 & $0.00 \%$ \\
\hline Gastric Bleeding & 4 & 563 & 544 & $1.382(0.393,4.869)$ & 0.614 & 0.308 & $16.7 \%$ \\
\hline Hematoma & 3 & 510 & 491 & $1.836(0.599,5.622)$ & 0.287 & 0.480 & $0.00 \%$ \\
\hline Mental Status Change & 3 & 510 & 491 & $0.862(0.572,1.298)$ & 0.476 & 0.725 & $0.00 \%$ \\
\hline \multicolumn{8}{|l|}{ Operative Outcomes } \\
\hline Surgery Length & 19 & 1458 & 1445 & $8.739(6.354,11.124)$ & $<0.0001 *$ & $72.7 \%$ & $<0.0001$ \\
\hline Blood Loss & 15 & 1142 & 1135 & $26.218(-3.572,56.008)$ & 0.085 & $80.4 \%$ & $<0.0001$ \\
\hline Hospital Length & 10 & 731 & 719 & $-0.330(-0.927,0.267)$ & 0.279 & $9.5 \%$ & 0.355 \\
\hline Required Blood Transfusion & 6 & 849 & 833 & $1.000(0.805,1.243)$ & 0.999 & $46 \%$ & 0.099 \\
\hline \multicolumn{8}{|l|}{ Mortality } \\
\hline 30-day & 9 & 762 & 748 & $1.046(0.703,1.557)$ & 0.824 & $0.00 \%$ & 0.663 \\
\hline 2 to 6 months & 10 & 911 & 822 & $0.943(0.786,1.131)$ & 0.526 & $0.00 \%$ & 0.946 \\
\hline 1-year & 8 & 855 & 834 & $0.852(0.727,0.998)$ & $0.047^{*}$ & $0.00 \%$ & 0.797 \\
\hline 2-year & 7 & 628 & 628 & $1.009(0.870,1.171)$ & 0.902 & $0.00 \%$ & 0.936 \\
\hline
\end{tabular}




\begin{tabular}{|lllllllll}
3 to 5 years & 4 & 667 & 674 & $1.032(0.970,1.098)$ & 0.324 & $0.00 \%$ & 0.854 \\
\hline
\end{tabular}

*OR or WMD considered statistically significant $(\mathrm{p}<0.05)$

RR, risk ratio (for dichotomous outcomes); WMD, weighted mean difference (for continuous outcomes); $\mathrm{Cl}$, confidence interval; UCH, uncemented hemiarthroplasty; $\mathrm{CH}$, cemented hemiarthroplasty

\section{Figures}

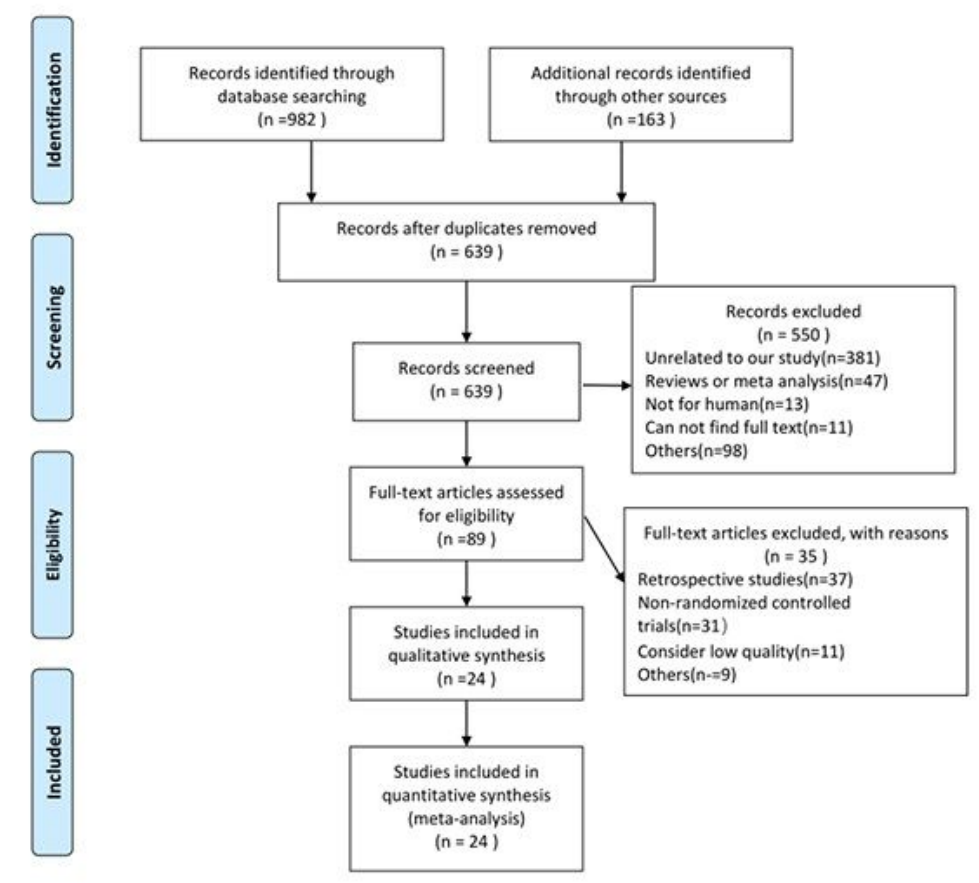

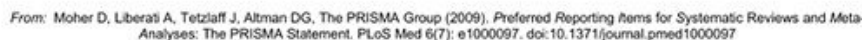

For more information, visit wwww.prisma-statement. org.

Figure 1

Figure 1 

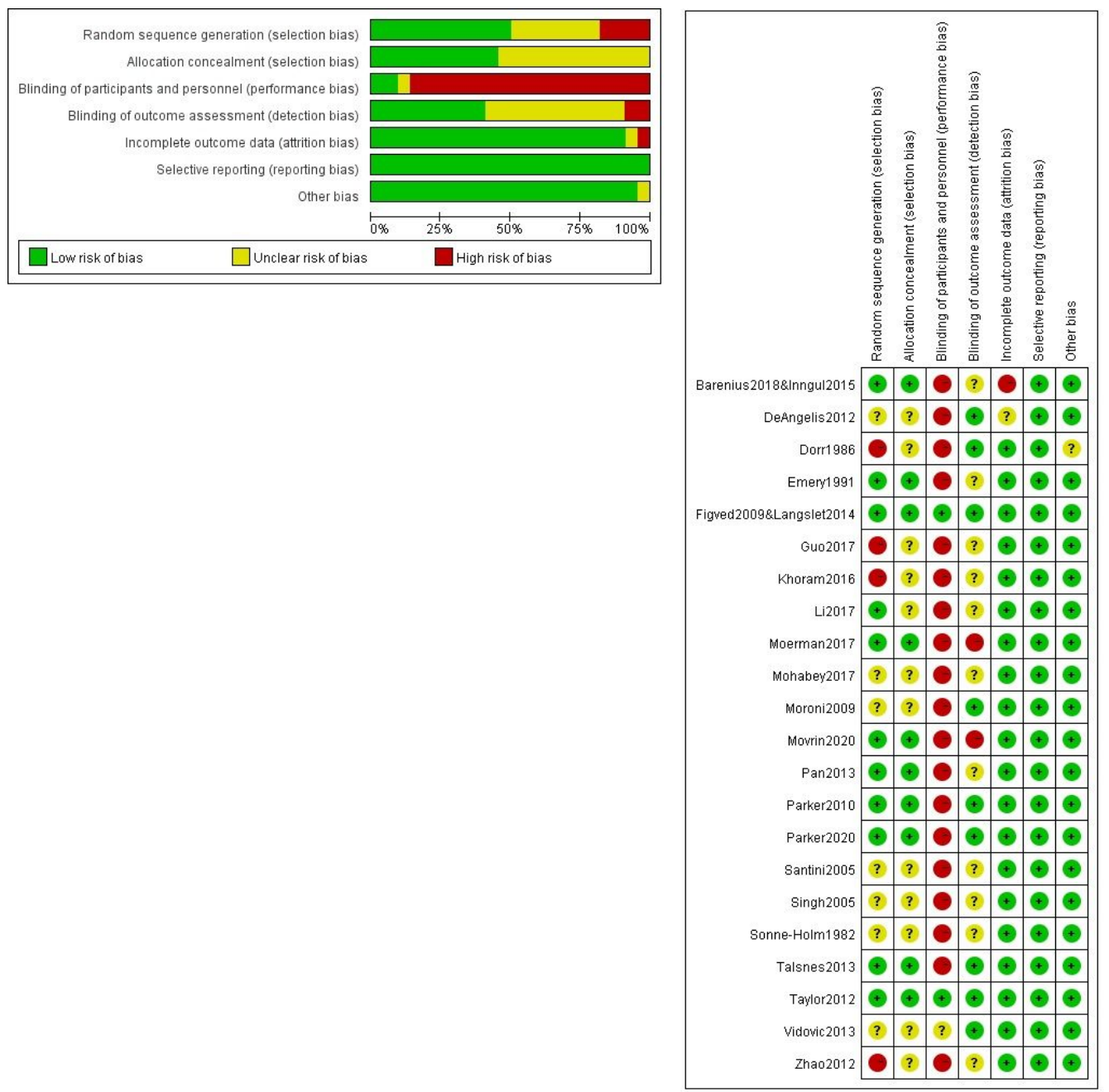

Figure 2

Figure 2
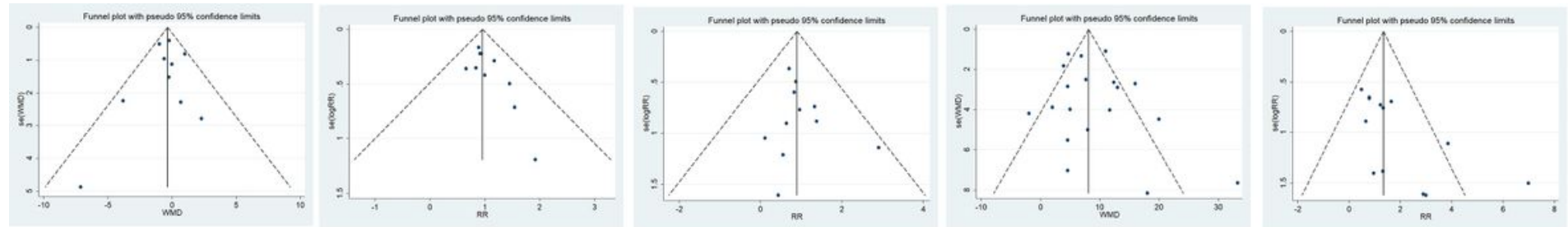

Figure 3

Figure 3 

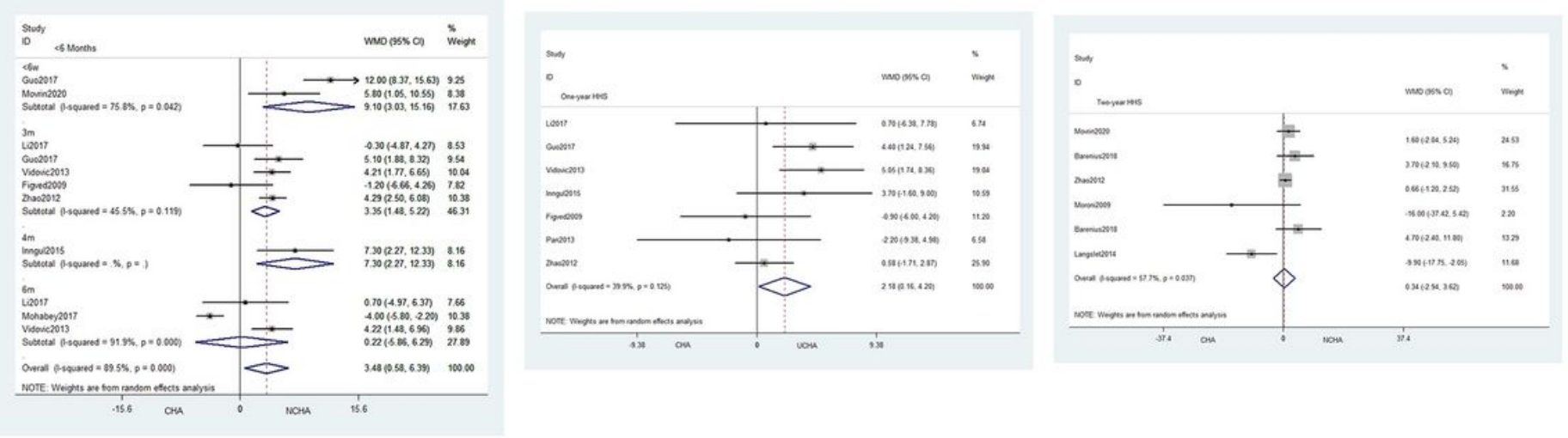

Figure 4

Figure 4

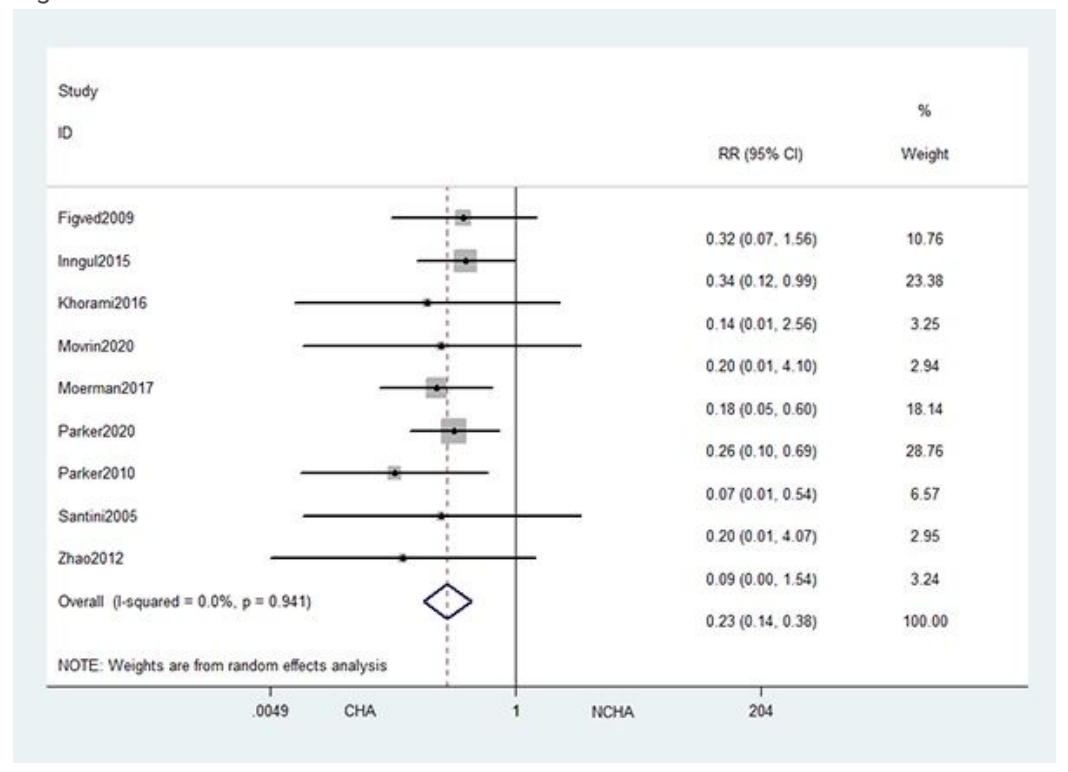

Figure 5

Figure 5

\section{Supplementary Files}

This is a list of supplementary files associated with this preprint. Click to download.

- PRISMAChecklist.doc 